\title{
Proyectos de desarrollo energético y los derechos económicos, sociales, culturales y ambientales: Una mirada desde la justicia interamericana de los derechos humanos*
}

\section{Energy development projects and economic, social, cultural and environmental rights: An inter- American justice of buman rights perspective}

Magda Yadira Robles Garza**

\section{RESUMEN}

La reforma constitucional en materia energética en México abrió al sector privado las inversiones en materia de hidrocarburos y electricidad. Sin embargo, el contexto constitucional en derechos humanos impone nuevas obligaciones a quienes emprendan proyectos en esta materia, tanto del sector privado como del público; por ello, los operadores jurídicos están obligados, desde la visión de los derechos humanos, a respetar estos principios. El juzgador enfrentará esta situación de conflicto, en donde el derecho a la salud cobra especial relevancia por lo que supone su disfrute para el ejercicio de otros derechos, por ejemplo, la vida y la integridad personal. Las líneas siguientes proponen analizar el escenario interamericano a través de los criterios razonados en las sentencias de la Corte de Derechos Humanos para proteger estos derechos en los proyectos de desarrollo e infraestructura que trajo consigo la reforma energética.

Palabras clave: energéticos, derechos humanos, derechos sociales, proyectos de desarrollo e infraestructura, medioambiente.

\section{ABSTRACT}

The constitutional reform on energy in Mexico allowed investment in hydrocarbons and electricity to the private sector. However, the constitutional context in human rights imposes new obligations on those who undertake projects in this area, both in the private sector and in the public sector; therefore, legal operators are hold responsible, by human rights, to respect these principles. The judge will face this situation of conflict, where the right to health takes on special relevance for what it means to enjoy other rights, such as personal life integrity. The main purpose of this text is to analyze the inter-American scenario through the outlined criteria in the rulings of The Human Rights Court. I order to protect these rights in the development and infrastructure projects that the energy reform will bring along.

Keywords: energy, human rights, social rights, development and infrastructure projects, environment.

* Artículo de reflexión recibido el 19 de mayo de 2015 y aceptado para publicación el 24 de enero de 2018

** Directora del Centro de Derechos Económicos, Sociales, Culturales y Ambientales (CEDESCA) en la Universidad Autónoma de Coahuila, México. (yadiraroblesgarza@gmail.com) orcid.org/0000-0002-5151-8606 
SUMARIO: 1. Introducción / 2. Vinculación conceptual del derecho energético con los derechos humanos / 3. Utilización del derecho interamericano de los derechos humanos para la determinación del contenido de los derechos. a. Derecho a la tierra, al territorio y a sus recursos naturales. b. Derecho a la consulta y el acceso a la información. c. Derecho a la vida y la integridad personal. d. Los Derechos económicos, sociales y culturales / 4. El trazo de la jurisprudencia del Tribunal Europeo de Derechos Humanos / 5. Algunos referentes recientes en la justicia mexicana / 6. Conclusiones

\section{INTRODUCCIÓN}

Las reformas constitucionales de los últimos años en México, especialmente la de derechos humanos en $2011 \mathrm{y}$, más recientemente, la reforma en materia energética en 2013, han puesto en el centro del debate la actividad del Estado, principalmente la labor de los jueces en el respeto de los derechos de las personas y los grupos de la sociedad que pudieran verse afectados por los grandes proyectos e inversiones que se generarán a partir de la entrada del sector privado nacional e internacional en la industria de los hidrocarburos y la electricidad.

En este sentido, el derecho a la protección de la salud cobra especial relevancia en la protección de personas y grupos vulnerables que puedan verse afectados por la privatización de los energéticos en México. El reconocimiento de los derechos humanos coloca a los operadores jurídicos ante la necesidad de contar con un marco jurídico aplicable y conocido por todos. El objetivo de las siguientes líneas será analizar este marco jurídico aplicable a partir de la incorporación de la jurisprudencia interamericana a nuestro sistema en materia de protección de los derechos sociales, haciendo énfasis en el aspecto del derecho a la salud. Sin duda, este nuevo panorama implica una labor de creatividad judicial muy diferente a la que tradicionalmente se ha realizado en México.

En efecto, en fecha reciente la Suprema Corte de Justicia de la Nación sostuvo que la jurisprudencia emitida por la Corte Interamericana de Derechos Humanos (Corte IDH) es vinculante para los jueces mexicanos atendiendo 
siempre a la situación más favorable para la persona, de acuerdo con el principio pro-persona inserto en el artículo primero constitucional. ${ }^{1}$

En cumplimiento de este mandato constitucional, el pleno del máximo tribunal sostuvo que:

los operadores jurídicos deben atender a lo siguiente: i) cuando el criterio se haya emitido en un caso en el que el Estado mexicano no haya sido parte, la aplicabilidad del precedente al caso específico debe determinarse con base en la verificación de la existencia de las mismas razones que motivaron el pronunciamiento; ii) en todos los casos en que sea posible, debe armonizarse la jurisprudencia interamericana con la nacional; y iii) de ser imposible la armonización, debe aplicarse el criterio que resulte más favorecedor para la protección de los derechos humanos. $^{2}$

Aquí resulta de la mayor importancia introducir una explicación. La Corte mexicana ha sido clara en señalar que la vinculación a los precedentes de la Corte IDH son de observancia obligatoria, ya sea que México haya sido parte o no. En otras palabras, los operadores jurídicos se encuentran obligados a analizar si el precedente resulta aplicable al ordenamiento mexicano. Este pensamiento es reforzado si partimos de la idea de que la jurisprudencia interamericana se construye en una línea histórica formada por sentencias que se encuentran interconectadas. Así, la determinación del contenido de los derechos humanos, como los derechos sociales, económicos, culturales y ambientales (DESCA), se ha construido sobre estándares que resultan aplicables en todos los estados que conforman la Organización de Estados Americanos.

Resalta el carácter tutelar y preventivo de las sentencias de la Corte IDH. En efecto, el carácter tutelar queda de manifiesto por el hecho de que la decisión pretende resolver un caso específico con base en la determinación de medidas de reparación a cargo del Estado infractor. Por otra parte, la función preventiva se desprende de los precedentes contenidos en las propias sentencias, los cuales conforman, junto con la decisión, un estándar mínimo que resulta aplicable para casos futuros y respecto a otros Estados ajenos a la

\footnotetext{
${ }^{1}$ Cossio, José R., "Primeras implicaciones del caso Radilla Pacheco", Cuestiones Constitucionales, Revista Mexicana de Derecho Constitucional, número 26, julio-diciembre 2012, pp. 32.

2 Contradicción de Tesis 293/2011, 3 de septiembre de 2013, Semanario Judicial de la Federación, décima época, libro 5, tomo I, Tesis: P./J.21/2014, p. 24. Registro 2006225.
} 
controversia que dio lugar a la emisión de la sentencia, pero que pueden tener casos judiciales similares cuyo criterio sea de ayuda en la solución interna de conflictos o preventivos para el mismo Estado.

En este sentido, partimos de la importancia de analizar los criterios de la justicia interamericana que serán vinculantes para los jueces $\mathrm{y}$, en general, todas las autoridades mexicanas ${ }^{3}$ a partir de la reforma energética, en lo que se refiere a los agentes del sector privado o público que participarán en la exploración, explotación o distribución y comercialización de los recursos naturales.

Sin embargo, esta situación no es inédita. Tribunales mexicanos -así como la Corte Interamericana de Derechos Humanos- han resuelto casos concretos sobre la base del derecho a la salud en diferentes ámbitos, como grupos indígenas, niños y niñas, grupos vulnerables de la población, entre otros. Las líneas siguientes tienen como objetivo central exponer las líneas jurisprudenciales creadas mediante las decisiones de la Corte IDH en los casos en que se vean involucrados proyectos de desarrollo en materia energética y su impacto con los DESCA, con el fin de demostrar que existe un estándar de protección de los DESCA en asuntos de proyectos de desarrollo creado por la instancia interamericana, a pesar de no contar con competencia expresa en la materia.

Para el logro del propósito anterior se presenta en primer término la vinculación de los proyectos de desarrollo que fueron impulsados con la reforma energética en México y su relación con los derechos humanos. Posteriormente, se analiza un grupo seleccionado de sentencias emitidas por la Corte IDH, destacando diversos rubros de los derechos, como el impacto en las comunidades indígenas y la protección a la tierra y los recursos naturales, la salud y alimentación, y en general los DESCA. Cabe mencionar que se agrega un apartado sobre algunas decisiones del Tribunal Europeo de Derechos Humanos (TEDH), en virtud de la referencia que de ellas hace la Corte de San José para apoyar su argumentación judicial; finalmente, algunos referentes recientes en los tribunales mexicanos en relación con estos proyectos de desarrollo y su relación con el ejercicio de los derechos humanos.

Cabe destacar que, además de las sentencias interamericanas, la Suprema Corte mexicana ha impulsado también el uso de peritajes culturales o antropológicos en la emisión de estas decisiones. Sin duda, todo ello conforma un

\footnotetext{
${ }^{3}$ Carpizo, Enrique, "El control de convencionalidad y su relación con el sistema constitucional mexicano. Hacia una simple actividad protectora de derechos humanos", Boletín Mexicano de Derecho Comparado, nueva serie, año XLVI, número 138, septiembre-diciembre 2013, pp. 939-971; especialmente p. 943.
} 
bloque de protección con fuerza vinculante para los jueces mexicanos de los diferentes niveles jurisdiccionales.

\section{Vinculación conceptual del DEREChO ENERGÉTico CON LOS DERECHOS HUMANOS}

La expansión mundial del sector privado y el correspondiente aumento de la actividad económica transnacional han traído en los últimos años la preocupación de las instancias nacionales e internacionales sobre las violaciones a los derechos humanos de las personas y comunidades afectadas por la realización de los grandes proyectos de desarrollo e infraestructura. ${ }^{4}$

Igualmente, desde el ámbito jurisdiccional se han generado esfuerzos para analizar el nuevo contexto global en el que se relacionan los gobiernos y las empresas y el papel que éstas tienen en los proyectos de desarrollo e infraestructura dentro de este marco económico de nuestro siglo. ${ }^{5}$

Conceptos como el neoextractivismo se han formulado para caracterizar este periodo histórico sin igual con otros procesos de explotación de la naturaleza. ${ }^{6}$ Se trata de un proceso masivo y creciente de explotación de bienes para su incorporación al mercado de la economía global. El rostro de este nuevo proceso no se centra como otrora en el petróleo y minería, sino en la explotación forestal o biocombustibles.

Por ejemplo, se incluyen aquí actividades como la mega minería a cielo abierto y la expansión de la industria petrolera y energética, que incluye el gas no convencional o gas shale, la construcción de grandes represas hidroeléctricas y la expansión de la frontera pesquera y forestal. En general, se incluyen los productos del modelo de agro-negocios y transgénicos, como el maíz y los biocombustibles, los cuales configuran los contornos de la naciente industria.

Sin duda, el escenario descrito comprende los grandes proyectos de desarrollo que son necesarios para el crecimiento que esta industria demanda. Así, veremos el surgimiento de enormes inversiones en materia de transportes (puertos, carreteras, corredores bioceánicos), energía (presas, hidroeléctricas, centrales eléctricas, plantas de energía geotérmica, nuclear o proyectos

\footnotetext{
${ }^{4}$ Comité de Derechos Humanos de Naciones Unidas, 2013.

${ }_{5}^{5}$ Protocolo de actuación para quienes imparten justicia en casos relacionados con proyectos de desarrollo e infraestructura, México, Suprema Corte de Justicia de la Nación, 2014, p. 9. Disponible en: https://www.scjn.gob.mx/ libreria/paginas/protocolos.aspx.

${ }^{6}$ Idem
} 
eólicos), agua (presas y trasvases entre regiones) y la explotación de recursos minerales, forestales y energéticos.

Para efectos de este trabajo, entenderemos como proyectos de desarrollo e infraestructura la definición adoptada por el "Protocolo de actuación para quienes imparten justicia en los casos relacionados con proyectos de desarrollo e infraestructura”, emitido por la Suprema Corte de Justicia de la Nación. Se trata de aquellos emprendimientos impulsados por empresas o por el Estado en zonas rurales o urbanas que tengan fines comerciales o que se lleven a cabo bajo el argumento del bien común; suponen la adquisición, disposición, arriendo u ocupación de espacios territoriales, generando un impacto sobre la vida de las personas o comunidades que las habitan, de las que ellos dependen, y una posible afectación a sus derechos humanos. ${ }^{7}$

Sin embargo, en la superficie de este modelo de crecimiento económico aparecen dos caras que deben ser analizadas: por un lado, estos proyectos se justifican no sólo constitucionalmente, sino además con el argumento del bien común que traerán consigo, como el acceso a servicios, la generación de empleos y el aumento en la riqueza de la región; por otro lado, estos beneficios deben ser analizados desde el punto de vista de las afectaciones que puedan traer en las personas o colectivos afectados. Esto significa un debate importante en el tema de los derechos humanos. ¿Qué derecho debe prevalecer en torno a un proyecto de infraestructura que suponga beneficios mayores y limitaciones para otros derechos?

Es decir, el análisis judicial de un proyecto de desarrollo desde la visión de los derechos humanos deberá recurrir al uso de la ponderación que permita determinar el escenario más favorable teniendo en cuenta el catálogo de derechos humanos. Esta situación de conflicto es lo que los tribunales han enfrentado recientemente. Factores como el bien común o bienestar general deben contraponerse con derechos como consulta, identidad cultural, derecho a la vida o integridad personal y derecho a la salud. En efecto, la mayor dificultad a la que los juzgadores se enfrentan es distinguir entre aquellos derechos que no admiten restricción alguna y otros que pueden ser limitados en virtud de otros.

Los grandes proyectos de desarrollo e infraestructura regularmente están sometidos a vigilancia de las autoridades del ramo, es decir, telecomunicaciones, recursos naturales y medioambiente, competencia económica, energía,

\footnotetext{
7 Ibidem, p. 11.
} 
entre otros. Sin embargo, desde el enfoque de los derechos humanos debemos identificarlos no sólo por sus requerimientos y características técnicas y científicas, sino por el impacto que su implementación puede traer en las comunidades o pueblos en los que se asientan. Así, desde esta perspectiva interesa saber los rasgos de los mismos y su proyección regulatoria desde los derechos humanos; especialmente, el enfoque en esta ocasión es en la protección a la salud.

Otro rasgo de este tipo de proyectos es la cantidad de recursos económicos y financieros con los que se impulsan. Esta peligrosa combinación de inversión y tiempo limitado en un determinado territorio puede generar rápidas y profundas transformaciones en los sitios donde se instalan. Esto significa cambios territoriales, destino de recursos naturales y transformación del entorno, que en muchos de los casos podrían ser de efecto irreversible. Este impacto trae consigo, por ejemplo, desocupación de tierras o movilidad de poblaciones enteras para la instalación de estos proyectos, como el caso de una presa hidroeléctrica y la explotación de petróleo o gas, por mencionar algunos supuestos.

Estos cambios en la forma de vida se pueden convertir en violación a los derechos de las personas o comunidades ahí alojadas, como el caso del derecho de propiedad privada, las afectaciones a la salud, la imposibilidad de acceso al agua y a la alimentación o el daño al medioambiente. Me refiero a que la falta de conocimiento y de transparencia de los procesos que se llevarán a cabo regularmente son cuestiones técnicas de complejidad para el no experto. Estas acciones implican reforzar la exclusión y la discriminación en la toma de decisiones de dichos proyectos.

Un aspecto relevante al respecto es que en México existen 31785 núcleos agrarios, de los cuales 29442 son ejidos y 2343 comunidades ocupan más de 101000000 de hectáreas, lo que representa 51\% del territorio nacional, superficie en la que habitan más de cinco millones de personas. El procurador agrario en México, Cruz Aguilar, señaló que si bien la propiedad social es más del 50\%, también lo es que el aprovechamiento de los recursos energéticos en las modalidades de exploración y extracción se da en gran medida en la propiedad social. ${ }^{8}$

En el caso de México, la reforma constitucional abrió al sector privado las inversiones en materia de hidrocarburos y electricidad, y se espera que

\footnotetext{
${ }^{8}$ Saldaña, Emmanuel, "Nuevo marco jurídico en materia energética establece acciones preventivas en materia social", Canal Judicial, 9 de abril de 2015. Disponible en: https://mail.google.com/mail/u/0/\#search/canal+judicial/ 14ca08a5a2d52a54. Consultado el 18 de mayo de 2015.
} 
en los próximos años veamos muchos de estos proyectos. Sin embargo, el contexto constitucional en derechos humanos impone nuevas obligaciones a quienes emprendan proyectos en esta materia, tanto del sector privado como del público. Por ello, tomando en cuenta este espacio internacional y nacional, resulta pertinente analizar los referentes de la justicia interamericana que nos permitan conocer el contenido y alcance de los derechos humanos de las personas y comunidades que puedan ser afectados por estos proyectos en materia energética en nuestro país, haciendo especial énfasis en aquellas obligaciones referidas a la protección de la salud. ${ }^{9}$

\section{UTILIZACIÓN DEL DERECHO INTERAMERICANO DE LOS DERECHOS HUMANOS PARA LA DETERMINACIÓN DEL CONTENIDO DE LOS DERECHOS}

En la jurisprudencia interamericana se encuentra un importante número de casos que abordan la dimensión sanitaria desde diferentes enfoques, como el derecho a la vida, a la dignidad de la persona, a la propiedad privada, así como en los derechos de identidad indígena y a la preservación de la cultura, además de otros derechos sociales, como el agua, la alimentación o la vivienda. ${ }^{10}$

Resulta pertinente señalar aquí que, por disposición del Protocolo Adicional a la Convención Americana de Derechos Humanos, conocido como Protocolo San Salvador, en el artículo 19.6 sólo los derechos a la educación y a la sindicación pueden dar lugar a un litigio ante la Corte IDH; por tal razón, los demás derechos económicos, sociales, culturales y ambientales (conocidos también como DESCA) no entran a litigio ante la Corte IDH como conceptos de violación directa.

Por lo tanto, la Corte IDH, como se verá enseguida, ha desarrollado la técnica de conexión o conectividad para señalar a los derechos sociales, como el derecho a la salud, el derecho al agua, el derecho a la alimentación o el derecho al medioambiente sano y adecuado, como derechos trasgredidos dentro de los derechos de libertad personal e integridad personal o el derecho a la vida. ${ }^{11}$ Algunos de estos casos se examinan enseguida.

\footnotetext{
${ }^{9}$ Talavera, Pedro, "El derecho humano a la salud frente a las condiciones biosanitarias del planeta", Revista Europea de Derechos Fundamentales, número 12, 2008, p. 100.

${ }^{10}$ Ventura Robles, Manuel, "Jurisprudencia de la Corte Interamericana en materia de derechos económicos, sociales y culturales", Revista IIDH, volumen 40, 2004, p. 107.

${ }^{11}$ Voto concurrente del Juez Eduardo Ferrer Mac-Gregor Poisot. Caso Suárez Peralta vs Ecuador. Excepciones Preliminares, Fondo, Reparaciones y Costas. Sentencia de 21 de mayo de 2013. Serie C No. 261. Disponible en: http:// www.corteidh.or.cr/docs/casos/articulos/seriec_261_esp.pdf.
} 


\section{a. Derecho a la tierra, al territorio y a sus recursos naturales}

En la Constitución mexicana se reconocen los derechos a la identidad cultural de los pueblos y comunidades indígenas. El artículo segundo constitucional, en la fracción VI, señala que tienen derecho a acceder al uso y disfrute preferente de los recursos naturales de los lugares que habitan y ocupan las comunidades, salvo aquellos que corresponden a las áreas estratégicas.

Sobre la propiedad de las poblaciones indígenas, el artículo 27 constitucional sólo señala que "la ley protegerá la integridad de las tierras indígenas”. Sin embargo, a partir del control de convencionalidad previsto en el artículo 1 de la Constitución, en este tema se recurre a los tratados internacionales que informan sobre el contenido del derecho. Así, tenemos el Convenio 169 de la Organización Internacional del Trabajo (OIT), que define el concepto de territorio como "la totalidad del hábitat de las regiones que los pueblos interesados ocupan o utilizan de alguna manera”. Puede verse que esta definición va más allá del concepto de tierra como un bien de mercado, ya que hace referencia a la dimensión vital y simbólica que tiene ese espacio para la reproducción de las culturas.

El mismo Convenio establece la obligación de brindar una protección especial de los recursos naturales que existen en las tierras de los pueblos, lo que implica la participación de los indígenas en la utilización, administración y conservación de los mismos. Interesa resaltar que el Convenio señala la obligación de consultar a los pueblos interesados, a fin de determinar si sus intereses -y derechos- serían perjudicados y de qué manera lo serían, antes de emprender proyectos extractivos. Volveré sobre éste más adelante. Por lo pronto, señalo que existe la obligación, por parte del Estado, de crear las condiciones o mecanismos para que los pueblos participen de los beneficios de las actividades extractivas y de recibir una indemnización equitativa por los daños que les pudieran ocasionar estas actividades.

En este sentido, la Corte IDH ha desarrollado ampliamente los alcances de este derecho. En varias de sus resoluciones y con base en el derecho de propiedad consagrado en el artículo 21 de la Convención Americana sobre Derechos Humanos (CADH), la Corte IDH enfatiza la importancia que la propiedad territorial tiene para los pueblos indígenas como base fundamental para el desarrollo de su cultura, su vida espiritual, su integridad y su supervivencia económica. Por ello, este derecho es reivindicado en sí mismo, pero también como condición para la realización de otra serie de derechos como 
los derechos a una vida digna, a la alimentación, al agua, a la salud, a la vida, a la dignidad, a la libertad de culto y de conciencia, a la libertad de asociación, a los derechos de la familia y al derecho a la residencia.

Así, ha interpretado la Corte IDH el derecho a la propiedad en casos donde las industrias extractivas y generadoras de energía han sido protagonistas de juicios que ponen de manifiesto la obligación del Estado de respetar estos derechos que pueden ser puestos en riesgo con estos proyectos de desarrollo.

Tres ejemplos dan muestra de este enfoque. El caso Yakye Axa vs Paraguay, ${ }^{12}$ el caso de la comunidad indígena Sawhoyamaxa vs Paraguay ${ }^{13}$ y el caso de la Comunidad Mayagna (Sumo) Awas Tingni vs Nicaragua. ${ }^{14}$ En ellos se utilizó el Convenio 169 de la Organización Internacional del Trabajo sobre pueblos indigenas y tribales en países independientes, para enfocar las disposiciones de la Convención Americana relativas al derecho de propiedad privada, previstas en el artículo 21 de dicha Convención. Bajo esta luz, la Corte IDH consideró que "la estrecha vinculación de los integrantes de los pueblos indígenas con sus tierras tradicionales y los recursos naturales ligados a su cultura que ahí se encuentren, así como los elementos incorporales que se desprenden de ellos, deben ser salvaguardados por la Convención Americana”. Por otra parte, entiende que

la cultura de los miembros de las comunidades indígenas corresponde a una forma de vida particular de ser, ver y actuar en el mundo, constituido a partir de esa estrecha relación con sus tierras tradicionales y recursos naturales, no sólo por ser estos su principal medio de subsistencia, sino además porque constituyen un elemento integrante de su cosmovisión, religiosidad y, por ende, de su identidad cultural. ${ }^{15}$

\footnotetext{
${ }^{12}$ Caso Comunidad Indigena Yakye Axa vs Paraguay, Serie C No. 125, Sentencia Fondo, Reparaciones y Costas de 17 de junio de 2005, Corte Interamericana de Derechos Humanos. Disponible en:http://www.corteidh.or.cr/docs/casos/ articulos/seriec_125_esp.pdf.

${ }^{13}$ Caso Comunidad Indigena Sawhoyamaxa vs Paraguay, Serie C No. 146, Sentencia Fondo, Reparaciones y Costas de 29 de marzo de 2006, Corte Interamericana de Derechos Humanos. Disponible en http://www.corteidh.or.cr/ docs/casos/articulos/seriec_146_esp2.pdf.

${ }^{14}$ Caso Comunidad Mayagna (Sumo) Awas Tingni vs Nicaragua, Serie C No. 66 y Serie C No. 79, Sentencia Fondo, Reparaciones y Costas de 31 de agosto de 2001, Corte Interamericana de Derechos Humanos. Disponible en: http:// www.corteidh.or.cr/docs/casos/articulos/Seriec_79_esp.pdf.

${ }^{15}$ Caso Comunidad Indigena Sawhoyamaxa vs Paraguay, Serie C No. 146, Sentencia Fondo, Reparaciones y Costas de 29 de marzo de 2006, párrafo 118; Caso Comunidad Mayagna (Sumo) Awas Tingni vs. Nicaragua, Serie C No. 66 y Serie C No. 79, Sentencia Fondo, Reparaciones y Costas de 31 de agosto de 2001, párrafo 149.
} 
En el caso Sawhoyamaxa, la comunidad había perdido sus tierras a favor de compañías privadas. Al iniciar el proceso de reivindicación, no tuvieron éxito. A consecuencia de las presiones recibidas por los propietarios de las fincas, los miembros de esta comunidad vivían en situación de pobreza extrema, bajos niveles de salud y atención médica, explotación laboral y restricciones para poseer cultivos y ganado propio; por ello, la mayoría de los miembros decidieron salir de la comunidad y se asentaron al borde de la carretera nacional en condiciones extrema miseria sin ningún tipo de servicios.

La Corte IDH resolvió que los miembros de la comunidad Sawhoyamaxa tienen el derecho a solicitar que se les devuelvan sus tierras tradicionales aun cuando éstas se encuentren en manos privadas y no tengan plena posesión de ellas. Además, señaló que cuando el Estado se vea imposibilitado a devolverlas, debe adoptar las medidas necesarias para restituir tanto las tierras tradicionales como los recursos comunales, por lo que cuando esto no sea posible para el Estado infractor, deberá entregarles tierras alternativas de igual extensión y calidad, que serán escogidas de manera consensuada por los miembros de los pueblos indígenas, conforme a sus propias formas de consulta y decisión. ${ }^{16}$

En el caso de la comunidad indígena Yakye Axa, las tierras de la comunidad fueron vendidas a empresas extranjeras. Estas compañías levantaron estancias ganaderas donde emplearon a algunos de los miembros de la comunidad pero, dadas las condiciones de vida que tenían en estas estancias, se trasladaron a otra extensión de tierra y desde 1996 se asentaron en el costado de la carretera, sin ningún servicio público disponible. En este caso, la Corte IDH fue explícita al decir que el desconocimiento del derecho ancestral de los miembros de las comunidades indígenas en sus territorios afectó otros derechos básicos como el derecho a la identidad cultural y la supervivencia misma de las comunidades y sus miembros. ${ }^{17}$

En ocasión de esta sentencia, la Corte IDH razonó sobre la violación al derecho a la vida. El Estado no otorgó las condiciones para una vida digna, en especial, si se trata de personas en situación de vulnerabilidad y riesgo, como es el caso. En el fallo afirmó que la comunidad sufrió de afectaciones especiales del derecho a la salud, la alimentación, el acceso a agua limpia, por lo que todo ello impacta en el derecho a una existencia digna y las condiciones

\footnotetext{
${ }^{16}$ Caso Comunidad Mayagna (Sumo) Awas Tingni vs Nicaragua, Serie C No. 66 y Serie C No. 79, Sentencia Fondo, Reparaciones y Costas de 31 de agosto de 2001, párrafo 135.

17 Ibidem, párrafo 147.
} 
básicas para el ejercicio de otros derechos humanos, como el derecho a la educación o el derecho a la identidad cultural. ${ }^{18}$

En el juicio Saramaka vs Surinam, ${ }^{19}$ la población sufrió la afectación al derecho sobre sus tierras debido a concesiones madereras y mineras otorgadas por el Estado en el territorio que habitaban. El análisis que realiza el tribunal de San José se basa en la interpretación del artículo 21 de la CADH, al grado de indicar que "el derecho a la propiedad protegido conforme al artículo 21 de la Convención Americana (...) confiere a los integrantes del pueblo Saramaka el derecho al goce de su propiedad de conformidad con su tradición comunitaria". ${ }^{20}$

Por ello, el reclamo por la titularidad de las tierras de los integrantes de los pueblos indígenas y tribales deriva de la necesidad de garantizar la seguridad y la permanencia del control y uso de los recursos naturales por su parte, lo que a su vez mantiene ese estilo de vida. De este análisis, se entiende que los recursos naturales que se encuentran en los territorios de los pueblos indígenas y tribales son "aquellos recursos naturales que han usado tradicionalmente y que son necesarios para la propia supervivencia, desarrollo y continuidad del estilo de vida de dicho pueblo".

Respecto a las concesiones otorgadas por el Estado para la exploración o extracción de los recursos naturales que existen en el territorio Saramaka, la Corte IDH sostuvo que las compañías madereras en el bosque podrían afectar los recursos de subsistencia de la comunidad. En palabras del tribunal, "la extracción de un recurso natural es muy probable que afecte el uso y goce de otros recursos naturales necesarios para la supervivencia de los Saramakes". ${ }^{21}$

\section{b. Derecho a la consulta y el acceso a la información}

El derecho a la consulta es uno de los derechos humanos de las comunidades indígenas que más relevancia e importancia ha tomado en las decisiones de la Corte IDH de los últimos años, precisamente por su relación con los proyectos de desarrollo en materia de hidrocarburos, electricidad, forestales, entre otros. En México, este derecho a la consulta se encuentra previsto en la fracción

\footnotetext{
${ }^{18}$ Ibidem, párrafo 167.

${ }^{19}$ Caso del Pueblo Saramaka vs Surinam, Serie C No. 172, Sentencia Excepciones preliminares, Fondo, Reparaciones y Costas de 28 de noviembre de 2007, Corte Interamericana de Derechos Humanos. Disponible en: http://www. corteidh.or.cr/docs/casos/articulos/seriec_172_esp.pdf.

20 lbidem, párrafos 122 y 95.

${ }^{21}$ Ibidem, párrafo 126.
} 
IX del apartado B del artículo 2 de la Constitución. El precepto señala como obligación del Estado, a través de las entidades y municipios, consultar a los pueblos y comunidades indígenas en la elaboración de un Plan Nacional de Desarrollo (previsto en el artículo 26 constitucional) y, en su caso, incorporar las recomendaciones o propuestas que hagan.

Sin embargo, el derecho internacional proporciona un marco regulador más amplio a partir del artículo 6.1 del Convenio 169 de la OIT, en el que se reconoce el derecho a una consulta. De acuerdo con dicho Convenio, es obligación de los Estados:

a) consultar con los pueblos indígenas, mediante procedimientos apropiados y a través de las instituciones representativas, cada vez que se prevean medidas legislativas o administrativas susceptibles de afectarles directamente;

b) establecer los medios a través de los cuales los pueblos puedan participar libremente en la adopción de decisiones en instituciones y organismos administrativos y de otra índole responsable de políticas y programas que les conciernan;

c) establecer los medios para el pleno desarrollo de las instituciones e iniciativas de esos pueblos y en los casos apropiados proporcionar los recursos necesarios para tal fin.

En otras palabras, la consulta a los pueblos indígenas será previa y abarca no solamente el uso de los recursos naturales, sino cualquier medida que pueda afectar directamente a estas comunidades. Los derechos protegidos por esta normativa pueden ser, como hemos visto, la propiedad, la cultura, la religión, la salud y el bienestar físico, y a materializar sus propias prioridades de desarrollo.

Sobre este derecho, la Corte IDH ha fijado precedentes para definir los alcances del derecho a la consulta en casos específicos. Recientemente, en el año 2012, se pronunció directamente sobre el ejercicio de este derecho en el caso pueblo indígena Kichwa de Sarayaku vs Ecuador. ${ }^{22}$

\footnotetext{
${ }^{22}$ En 2004 se registró el estatuto del pueblo originario Kichwa de Sarayaku, pero en 1996 se había suscrito un contrato de exploración de hidrocarburos y explotación de petróleo en el bloque 23 de la región amazónica entre una empresa estatal y el consorcio formado por dos empresas privadas de capital extranjero. El espacio territorial que se otorgó para la concesión comprendia 200000 hectáreas dentro de las que habitaban comunidades y pueblos indigenas, como el pueblo en cuestión.
} 
La población negó en repetidas ocasiones la entrada a su territorio a la explotación petrolera; sin embargo, en 2002 las empresas privadas iniciaron la fase de exploración sísmica, con lo cual entró una de las compañías al territorio ancestral. Esto ocasionó que la comunidad detuviera sus actividades económicas, administrativas y escolares, y se organizaran para impedir la entrada. En respuesta a esto, la empresa abrió trochas sísmicas, siete helipuertos, destruyó cuevas, fuentes de agua y ríos subterráneos, taló árboles y plantas de valor medioambiental, que además eran el sustento alimentario de la tribu de Sarayaku.

Ocho años después, en 2010, la empresa estatal de petróleo firmó un convenio de terminación con una de las compañías privadas para la exploración y explotación del petróleo crudo en esta zona, pero el pueblo no fue informado de esto ni de los términos de la negociación del acta de terminación.

Tal como lo había establecido en procesos anteriores, la Corte IDH reiteró el criterio de que el reconocimiento del derecho a ser consultados está cimentado en el respeto al derecho a la cultura propia o identidad cultural, los cuales deben ser garantizados. ${ }^{23}$ Sobre este derecho, la Corte facilitó tres líneas precisas de actuación gubernamental.

Primero, señaló que el Estado debe consultar activamente y de manera informada con dicha comunidad y según sus costumbres y tradiciones, en el marco de una comunicación constante entre las partes. Además, las consultas deben realizarse de buena fe, a través de procedimientos culturalmente adecuados y tener como fin llegar a un acuerdo; finalmente, debe tomar en cuenta los métodos tradicionales del pueblo o comunidad para la toma de decisiones, ya que el no cumplimiento de esta obligación compromete la responsabilidad internacional del Estado en el respeto a sus derechos. ${ }^{24}$

Ahora bien, en el caso de que no se lograra el acuerdo o consentimiento en el proceso de consulta, el Estado podría hacer una propuesta si garantiza que no conlleva impactos significativos sobre los derechos de estos pueblos, tales como su derecho a establecer sus propias prioridades para el desarrollo como parte de su derecho a la libre determinación, el derecho a la salud y un

\footnotetext{
${ }^{23}$ Caso del Pueblo indigena Kichwa de Sarayaku vs Ecuador, Serie C No. 245, Sentencia Fondo y Reparaciones de 27 de junio de 2012, Corte Interamericana de Derechos Humanos, párrafo 159. Disponible en: http://corteidh.or.cr/ docs/casos/articulos/seriec_245_esp.pdf.

${ }_{24}$ Ibídem, párrafo 177. Con respecto a lo anterior, la jurisprudencia de la Corte interamericana evidencia que el consentimiento sería exigible cuando los derechos de los pueblos indigenas que son esenciales para su supervivencia se pongan en riesgo. Ello pudiera comprender, no solo los proyectos de inversión o desarrollo sino también las actuaciones del Estado para el reasentamiento o traslados poblacionales y el almacenamiento o desecho de materiales peligrosos en territorios indigenas.
} 
medio ambiente sano, el derecho a la cultura y a la religión, y los derechos de los pueblos indígenas sobre sus tierras y recursos naturales de acuerdo con sus usos y costumbres.

Finalmente, la Corte consideró que la falta de consulta del pueblo $S a$ rayaku afectó su identidad cultural debido a que la intervención y la destrucción del patrimonio cultural implicaron una falta grave de respeto a su identidad social y cultural, costumbres, tradiciones, cosmovisión y su modo de vivir, produciendo preocupación y tristeza entre la comunidad. ${ }^{25}$

Otro aspecto que incide en estos proyectos, sin duda, es el impacto medioambiental. En el caso Saramaka vs Surinam, la sentencia de la Corte IDH señaló que las concesiones mineras se emitieron sin realizar o supervisar evaluaciones previas de impacto ambiental y social, y sin garantizarles a sus miembros una participación razonable de los beneficios. ${ }^{26}$ Interesante es el añadido del veredicto donde se señala que el Estado debe asegurarse de que los miembros del pueblo Saramaka tengan conocimiento de los posibles riesgos, incluidos los riesgos ambientales y de salubridad, a fin de que acepten el plan de desarrollo o inversión propuesto con conocimiento y de forma voluntaria.

En efecto, por ejemplo, si los proyectos de inversión o desarrollo afectaran el modo de vida o subsistencia de los pueblos indígenas o impliquen el reasentamiento o traslados poblacionales y el almacenamiento o desecho de materiales peligrosos en territorios indígenas; o bien, si no hay acuerdo o consentimiento mediante el proceso de consulta, el Estado podría proceder con una propuesta sólo si pudiera garantizar que no tuviese impactos significativos sobre los derechos de estos pueblos, tales como su derecho a establecer sus propias prioridades para el desarrollo como parte de su derecho a la libre determinación, el derecho a la salud y un medio ambiente sano, el derecho a la cultura y a la religión, y los derechos de los pueblos indígenas sobre sus tierras y recursos naturales de acuerdo con sus usos y costumbres.

En ningún caso deberían ser vulnerados estos derechos; aun en los casos en que el consentimiento no fuera estrictamente necesario, el Estado debe actuar de manera que respete y proteja los derechos humanos de los pueblos indígenas, lo que podría incluir la aplicación de otras salvaguardas, tales como el establecimiento de medidas de mitigación y compensación.

${ }^{25}$ Ibidem, párrafo 220.

${ }^{26}$ Ibidem, párrafo 156. 


\section{c. Derecho a la vida y la integridad personal}

El uso de tratados internacionales en la interpretación de la CADH abre un rol importante para delimitar el contenido y los alcances del derecho a la protección de la salud. ${ }^{27}$ Varios de estos instrumentos se relacionan con la vida y la salud humana, por ejemplo, el Convenio de Estocolmo sobre Contaminantes Orgánicos Persistentes. En el caso Comunidad Mayagna (Sumo) Awas Tingni vs Nicaragua en 2001, la Corte señaló que "los tratados de derechos humanos son instrumentos vivos cuya interpretación tiene que adecuarse a la evolución de los tiempos, y en particular con las condiciones de vida actuales. En este sentido, encuentran aplicabilidad los principios de progresividad y pro homine, los cuales inspiran la protección de los derechos". ${ }^{28}$

En este caso, la Corte IDH destacó la importancia de los estudios de impacto ambiental para prevenir riesgos y adoptar las medidas de seguridad necesarias, así como la importancia del consentimiento y participación de las comunidades en las decisiones sobre proyectos económicos. El caso Velásquez Rodríguez, resuelto en 1998, sentó las bases en casos que involucran daños al medioambiente y a la salud pública en relación con la responsabilidad del Estado y las actuaciones de terceros. Frente a los actos de particulares, la obligación del Estado de velar por el respeto a los derechos humanos cobra especial relevancia no por el hecho en sí mismo, sino por la falta de la debida diligencia para prevenir la violación o para tratarla por parte del Estado. ${ }^{29}$

Por otro lado, en la sentencia dictada en el caso Pueblo Indígena Kichwa de Sarayaku vs Ecuador, la Corte IDH recordó que el Estado es responsable de cualquier situación de riesgo contra el derecho a la vida. ${ }^{30}$ En este caso, reflexionó que la empresa petrolera realizó, con la anuencia y protección del Estado, el desbroce de senderos y sembró explosivos dentro del territorio que incluye a la comunidad Sarayaku; por lo tanto, el Estado fue responsable de poner en riesgo los derechos a la vida e integridad personal de los miembros del pueblo. ${ }^{31}$

\footnotetext{
${ }^{27}$ Como lo señaló en el caso Gudiel Alvarez y otros (Diario Militar) vs Guatemala. Sentencia de Fondo, Reparaciones y Costas de 20 de noviembre de 2012, párrafo 330.

${ }^{28}$ Caso Comunidad Mayagna (Sumo) Awas Tingni vs Nicaragua, sentencia de Fondo, Reparaciones y Costas de 31 de agosto de 2001.

${ }^{29}$ Caso Velásquez Rodríguez vs Honduras, Serie C No. 4, Sentencia de Fondo de 29 de julio de 1988, Corte Interamericana de Derechos Humanos. Disponible en: http://www.corteidh.or.cr/docs/casos/articulos/seriec_04_esp.pdf.

${ }^{30}$ Caso del Pueblo indigena Kichwa de Sarayaku vs Ecuador, Serie C No. 245, Sentencia Fondo y Reparaciones de 27 de junio de 2012, párrafo 245.

${ }^{31}$ Ibidem, párrafo 249.
} 
El derecho a la vida y a la integridad personal nuevamente fue pronunciado por la Corte al resolver el caso Comunidad Indígena Sawhoyamaxa ${ }^{32}$ Dijo la Corte que las autoridades de Paraguay sabían - partir de 1997- de la existencia de una situación de riesgo real e inmediato para la vida de un individuo o de un grupo de individuos determinados y no tomaron las medidas necesarias dentro del ámbito de sus atribuciones, que podrían esperarse para prevenir o evitar ese riesgo. ${ }^{33}$

En este sentido, es significativa la sentencia porque el Tribunal determinó responsabilidad al Estado por la situación de vulnerabilidad en la que permanecían los miembros de esta comunidad; especialmente, los niños, las mujeres embarazadas y los ancianos, así como el hecho de su mortandad. ${ }^{34}$

El despojo de la propiedad de la tierra trajo consigo el desempleo, el analfabetismo, las tasas de morbilidad por enfermedades evitables, la desnutrición y las limitaciones de acceso y uso de los servicios públicos de salud y agua potable, así como la marginación por causas económicas, geográficas y culturales. Todo ello constituyó un impedimento para acudir a los centros asistenciales de salud. En este sentido, resulta gráfico el argumento empleado en la sentencia al considerar que los enfermos que pudieron llegar a un centro asistencial lo hicieron de manera tardía o fueron tratados de forma denigrante para la condición humana. De ahí que las muertes de los miembros de la comunidad sean atribuibles al Estado. Especial tratamiento hace la sentencia en cuestión sobre el derecho a la vida de los niños y de las mujeres embarazadas al no contar con el acceso adecuado a servicios de atención médica. ${ }^{35}$

El mismo análisis lo encontramos en la sentencia dictada en razón del caso Comunidad Indígena Yakye Axa vs Paraguay, ${ }^{36}$ en donde la Corte IDH llegó a la conclusión de que el Estado, al generar condiciones que llevaron a la vulneración del derecho a la vida digna y no cumplir con el deber de desarrollo progresivo de los derechos, afectó otros derechos, como el derecho a la salud, el derecho a un medioambiente sano, el derecho a la alimentación y al agua limpia, el derecho a la educación y el derecho a los beneficios de la cultura. ${ }^{37}$ También, en esta sentencia hace un especial pronunciamiento

\footnotetext{
${ }^{32}$ Caso Comunidad Indigena Sawhoyamaxa vs Paraguay, Serie C No. 146, Sentencia Fondo, Reparaciones y Costas de 29 de marzo de 2006, cit.

33 Ibidem, párrafo 155.

${ }^{34}$ Ibidem, párrafo 159.

35 Ibidem, párrafos $168,174,177$ y 178.

${ }^{36}$ Caso Comunidad indígena Yakye Axa vs Paraguay, Serie C No. 125, Sentencia Fondo, Reparaciones y Costas de 17 de junio de 2005.

${ }^{37}$ Ibidem, párrafos 163 y 167.
} 
en defensa de los derechos de los niños y personas de edad avanzada de la comunidad..$^{38}$

\section{d. Los derechos económicos, sociales y culturales}

En México, la reforma a los derechos humanos de 2011 abrió un escenario importante para la protección de los derechos sociales, económicos y culturales. En efecto, el reconocimiento de ciertos derechos sociales, como los derechos a la salud, a la educación, al trabajo, a la vivienda, al medioambiente y al desarrollo, tienen especial configuración normativa al imponer esencialmente deberes al Estado. Veamos algunos ejemplos de la interpretación de la Corte IDH en torno a esta categoría de derechos humanos.

El derecho al agua y a la alimentación fue motivo de análisis en relación con el derecho a la salud en ocasión del caso Comunidad Indígena Xákmok Kásek vs Paraguay. ${ }^{39}$ Aquí la Corte sustentó que las afectaciones al derecho a la vida digna se ven reflejadas en la falta de agua en cantidad y calidad suficiente que no los exponga a enfermedades, ${ }^{40}$ así como contar con alimentación en cantidad y calidad suficientes para las necesidades básicas diarias y el acceso a servicios de salud y a servicios educativos para los niños y niñas de la comunidad. ${ }^{41}$

Como puede observarse, esta sentencia es del mayor interés porque la afectación a estos derechos se deriva de analizar las condiciones de vida de los miembros de la comunidad. Así, llegó a la conclusión de que debido a la falta de restitución de sus tierras tradicionales, la pérdida paulatina de su cultura y la larga espera que han debido soportar en el transcurso del ineficiente procedimiento administrativo, así como las condiciones de vida miserables, la muerte de varios de sus miembros y el estado general de abandono en el que se encuentran generan sufrimientos que afectan la integridad psíquica y moral de todos los miembros de la comunicad, todo ello constituye una violación al artículo 5 de la CADH en perjuicio de los miembros de la comunidad. ${ }^{42}$

\footnotetext{
${ }^{38}$ Ibidem, párrafos 172 y 175.

${ }^{39}$ Caso Comunidad indigena Xákmok Kásek vs Paraguay, Serie C No. 214, Sentencia Fondo, Reparaciones y Costas de 24 de agosto de 2010, Corte Interamericana de Derechos Humanos. Disponible en: http://www.corteidh.or.cr/ docs/casos/articulos/seriec_214_esp.pdf.

40 Ibidem, párrafo 195.

41 Ibidem, párrafos 200, 208 y 213.

42 Ibidem, párrafo 244.
} 
Por otro lado, el derecho a la vivienda es uno de los derechos que también debe considerarse dentro de las afectaciones a derechos con motivo de los proyectos de desarrollo e infraestructura. La Corte IDH ha desarrollado un concepto amplio sobre el derecho a la propiedad, en el que incluye el derecho a una vivienda adecuada, que considera conceptos como bienes materialmente definidos y las cosas inmateriales. ${ }^{43}$

El mismo criterio sostuvo en el caso Salvador Chiriboga vs Ecuador,44 cuando señaló que un concepto amplio de propiedad abarca, entre otros, el uso y goce de los bienes, definidos como cosas materiales apropiables, así como todo derecho que pueda formar parte del patrimonio de una persona. Dicho concepto comprende todos los muebles e inmuebles, los elementos corporales e incorporales y cualquier otro objeto inmaterial susceptible de valor. ${ }^{45}$

En relación con el derecho a la alimentación, la Corte IDH también ha establecido criterios sobre el cumplimiento de este derecho por parte del Estado. En particular, en el caso Xákmok Kásek vs Paraguay, la Corte IDH hizo un atrayente análisis sobre la cantidad de alimentos que el Estado proporcionó a esta comunidad indígena durante varios periodos (mayo de 2009 a marzo de 2010). Llegó a la conclusión de que lo otorgado por el Estado en este periodo correspondía a $0.29 \mathrm{~kg}$ de alimentos por persona por día. En consecuencia, estimó que esta cantidad de alimento es insuficiente para satisfacer medianamente las necesidades básicas diarias de alimentación de cualquier persona. ${ }^{46}$

En este mismo asunto, la Corte realizó el mismo análisis sobre los litros de agua por día que recibía cada persona de la comunidad. De acuerdo con el estándar internacional, señaló que una persona requiere de mínimo 7.5 litros por día para satisfacer el conjunto de necesidades básicas, es decir, incluye alimentación e higiene. Aplicando esta medición, arribó a la conclusión de que las gestiones del Estado para proveer a los miembros de la comunidad de agua suficiente y calidad adecuada no fueron suficientes y no demostraron que los miembros de la comunidad tengan acceso a fuentes seguras de agua, por lo cual los expuso a riesgos y enfermedades. ${ }^{47}$

\footnotetext{
${ }^{43}$ Caso Acevedo Buendía y otros vs Perú, Serie C No. 198. Sentencia de excepción preliminar, Fondo, Reparaciones y Costas de 01 de julio de 2009, Corte Interamericana de Derechos Humanos, párrafo 84. Disponible en: http://www. corteidh.or.cr/docs/casos/articulos/seriec_198_esp.pdf.

${ }^{44}$ Caso Salvador Chiriboga vs Ecuador. Serie C No. 179. Resolución de la Corte Interamericana de Derechos Humanos del 15 de mayo de 2011. Disponible en: http://www.corteidh.or.cr/docs/casos/articulos/seriec_179_esp.pdf.

45 Ibidem, párrafo 55.

${ }^{46}$ Caso Comunidad Indigena Xákmok Kásek vs Paraguay, Serie C No. 214, Sentencia Fondo, Reparaciones y Costas de 24 de agosto de 2010, párrafo 200.

${ }^{47}$ Ibidem, párrafos 195 y 196.
} 
4. El trazo de la jurisprudencia del tribunal europeo de Derechos HUMANOS

En materia de responsabilidad del Estado en los casos que impliquen proyectos o acciones industriales que pongan en peligro los derechos humanos, la Corte Europea se ha pronunciado en diversas ocasiones para tratar el derecho al medioambiente y salud pública. Como sabemos, la Corte IDH emplea en sus sentencias referencias a otros tribunales $\mathrm{u}$ organismos internacionales para la interpretación del alcance y contenido de derechos previstos en la CADH y en los tratados internacionales. ${ }^{48}$ Uno de ellos, quizá la referencia más importante, es sin duda el Tribunal Europeo de Derechos Humanos. ${ }^{49}$ Veamos el criterio de este Tribunal para casos que involucren este tipo de proyectos.

Es relevante el caso Oneryildiz vs Turkey, con sentencia del 30 noviembre de 2004, donde el Estado resultó responsable de la destrucción de la vivienda del demandante, la cual fue construida en terrenos que rodean un vertedero de residuos utilizado por cuatro comunidades urbanas. En 1993 se produjo una explosión de metano que destruyó las casas situadas alrededor y causó la muerte de nueve personas. El demandante argumentó que no se habían tomado medidas necesarias para evitar una explosión a pesar de un informe pericial presentado a las autoridades sobre la necesidad de actuar de forma preventiva.

En este caso, el Tribunal Europeo de Derechos Humanos sostuvo que se había producido una violación al artículo 2 de la Convención a causa de la falta de medidas adecuadas para evitar la muerte accidental. El Tribunal observa, en particular, que el Gobierno turco no había proporcionado a los habitantes de los barrios marginales la información necesaria sobre los riesgos que corrían al vivir allí; incluso si lo hubiera hecho, se mantuvo como responsable de no haber tomado las medidas prácticas necesarias para evitar los riesgos para la vida de las personas.

La Corte Europea ha aplicado el criterio de responsabilidad del Estado por actitud pasiva frente a terceros contaminantes, por ejemplo, en López Ostra vs España. Aquí sostuvo que la autoridad era responsable por haber permitido la instalación de una planta contaminante en tierras propiedad de la ciudad

\footnotetext{
${ }^{48}$ Como lo dejó asentado en el Caso Masacre de Santo Domingo vs Colombia. Sentencia de Excepciones Preliminares, Fondo y Reparaciones de 30 de noviembre de 2012.

49 Tribunal Europeo de Derechos Humanos, Caso Oneryildiz vs Turkey. 24 de noviembre de 2004. Disponible en: http://hudoc.echr.coe.int/sites/eng-press/pages/search.aspx?i=003-1204313-1251361. Otro caso similar se refiere a la exposición de la radiación nuclear y sus efectos en la salud en L.C.B. vs the United Kingdom (application no. 23413/94). Disponible en: http://hudoc.echr.coe.int/sites/fra/pages/search.aspx?i=001-58176.
} 
y con subsidios del Estado. ${ }^{50}$ Por otro lado, en el caso Tuskin vs Turquía, la Corte estableció que el Estado puede incurrir en responsabilidad por no tomar en cuenta los posibles peligros a los que expone a la población al permitir actividades mineras, aun sin que se hayan comprobados daños a la salud o a los hogares de los demandantes.

En Vilnes and Others vs Norway, del 5 de diciembre de 2013, la Corte Europea de Derechos Humanos sostuvo que había habido una violación del derecho al respeto de la vida privada, a causa de la incapacidad de las autoridades noruegas para asegurar que los demandantes (buzos de aguas profundas) recibieran información esencial que les permitiera evaluar los riesgos para su salud y vida, resultante de la utilización de tablas de descompresión rápida. ${ }^{51}$

\section{Algunos referentes recientes en la justicia mexicana}

En años recientes, el caso de la Tribu Yaqui llamó la atención en esta materia porque en el 2013 la Suprema Corte de Justicia de la Nación suspendió la construcción del proyecto hídrico en el estado de Sonora, que consistía en el trasvase del agua de un río para el abastecimiento del vital líquido a la ciudad de Hermosillo, capital de aquel estado. La tribu Yaqui consideró lesionado su derecho al agua, pues en 1940, por decreto del entonces presidente Lázaro Cárdenas, esta comunidad tenía el derecho de disponer del 50\% del agua del río para su subsistencia. Alegan el daño medioambiental causado en el territorio yaqui, pero sobre todo se alega que se vieron despojados del derecho al agua, que les pertenecía, y que el proyecto se llevó a cabo sin realizar ningún tipo de información ni consulta hacia la comunidad indígena. ${ }^{52}$

Interesa aquí resaltar que la Suprema Corte mexicana usó la jurisprudencia del caso Sarayaku y el Convenio 169 de la OIT para determinar que la consulta debió ser previa, culturalmente adecuada, informada y de buena fe,

\footnotetext{
${ }^{50}$ Caso Lopez Ostra vs Spain, del 9 de diciembre de 1994. Disponible en: http://hudoc.echr.coe.int/sites/fra/pages/ search.aspx?i=001-57905.

${ }^{51}$ Los demandantes están incapacitados como consecuencia de buceo en el Mar del Norte para las empresas petroleras durante el período pionero de la exploración de petróleo (1965-1990). Todos los solicitantes se quejaron de que Noruega no había adoptado las medidas adecuadas para proteger la salud de los buzos de aguas profundas. Todos ellos también alegaron que el Estado no había podido proporcionarles información adecuada sobre los riesgos que implican tanto submarinismo como el buceo de prueba. Caso Vilnes and Others vs Norway Disponible en: http://hudoc.echr.coe.int/sites/eng-press/pages/search.aspx?i=003-4598614-5560664.

52 El proyecto consiste en la construcción y operación de: a) una obra de toma vertical en la presa El Novillo, b) una estación de rebombeo horizontal (cárcamo de bombeo), c) un acueducto de acero para la distribución de agua nacional y d) una línea de transmisión eléctrica, sin que se desprenda pronunciamiento respecto a la restricción de los derechos de disposición.
} 
con la finalidad de llegar a un acuerdo y para garantizar la subsistencia de la tribu, para que fuese escuchada para efectos de la operación (no construcción) del acueducto.

Sin duda, la resolución de la Primera Sala de la Suprema Corte de Justicia aporta valor en materia de derecho al territorio, derecho al agua y consulta a pueblos y comunidades indígenas de acuerdo con sus usos y costumbres, pues reconoce, por primera vez en México, los estándares interamericanos en materia de derecho a la consulta de los pueblos indígenas.

También, la Suprema Corte mexicana determinó que el derecho a la salud no se puede reducir a la salud física del individuo, sino que va más allá, en tanto comprende el buen estado mental y emocional de una persona. ${ }^{53}$ De acuerdo con esto, el derecho a la salud implicará, por lo tanto, la obtención de un determinado bienestar general que incluye el estado físico, mental, emocional y social. Esto es relevante para nuestro estudio, ya que el hecho de los desalojos puede tener impactos negativos psicológicos en las personas que los sufren, por las condiciones de estrés a las que se encuentran sometidas.

Más recientemente, en abril de 2015, el Segundo Tribunal Colegiado en Materia Administrativa del Séptimo Circuito, con sede en Boca del Río (Veracruz), concedió una suspensión que protege el entorno ecológico y el derecho humano al agua en comunidades indígenas, y suspende la construcción de mini-centrales eléctricas. El tribunal aplicó el principio in dubio pro natura, que establece que, de existir peligro o amenaza de daños graves o inminentes sobre elementos de biodiversidad, la ausencia de certeza científica no es obstáculo para dictar medidas que conserven el medio ambiente..$^{54}$

Esta decisión evitará que se afecte el entorno ecológico de las comunidades indígenas, en específico el derecho humano al agua, evitándose un daño irreversible en los manantiales situados en dichos sectores desprotegidos de la vida nacional.

En la misma temática resolvió en 2015 los recursos de revisión ${ }^{55}$ contra los amparos que las comunidades indígenas de Yucatán y Campeche habían ganado contra los permisos otorgados por Sagarpa a una empresa trasnacional

\footnotetext{
${ }^{53}$ Amparo en revisión, 6 de enero de 2009. Publicada en Gaceta del Semanario Judicial de la Federación, novena época, tomo XXX, p. 6. Registro 165826.

54 "Conceden suspensión de plano a comunidades indígenas de Veracruz". Canal Judicial, 23 de abril de 2015. Disponible en: https://mail.google.com/mail/u/0/\#search/canal/14ce7de1d2591167.

${ }_{55}$ Los asuntos fueron radicados en la Segunda Sala. Los amparos provenientes de las comunidades indígenas de Campeche (Segunda Sala, SCJN, AR 498/2015, AR 499/2015, AR 500/2015, AR 270/2015 y AR 410/2015) y de Yucatán (Segunda Sala, SCJN, AR 198/2015) fueron decididos el 4 de noviembre de 2015 y confirmaron las sentencias recurridas al reafirmar la vulneración de los derechos de los pueblos indígenas y la protección al medioambiente.
} 
para liberación de la soya transgénica. En la demanda de amparo original las comunidades alegaron que el derecho a la consulta libre, responsable e informada no fue realizada a través de los medios idóneos para que la comunidad se manifestara. En este sentido, el juez de distrito otorgó el amparo suspendiendo el permiso otorgado a la empresa hasta en tanto no se llevase a cabo la consulta por los medios idóneos y adecuados a las comunidades, pues consideró que el mecanismo empleado por la autoridad en línea, empleando el internet, no permitía el acceso para la realización de la consulta que la Corte IDH y el Convenio de la OIT numero 169 señalaban como requisito previo.

En tal sentido, la Suprema Corte de Justicia de México confirma el amparo otorgado. Fue cuestionada la sentencia desde diversos ángulos, que ahora no toca reproducir, sólo basta con señalar aquí que, de acuerdo con los ministros que resolvieron los casos, el amparo otorgado inicialmente debía cambiarse para proteger solamente a las comunidades afectadas, es decir, Yucatán y Campeche; por tanto, las comunidades indígenas de San Luis Potosí, Michoacán y otras promoventes quedaron sin protección en la resolución de la revisión. ¿Por qué ha sido esto importante para nuestro estudio?

La respuesta nos viene dada del planteamiento que hace la Corte IDH en cuanto a la protección de los recursos naturales y el medio ambiente de todos los territorios afectados para el futuro y la aplicación del principio de precaución.

En efecto, recientemente en la Opinión Consultiva número 23, de la Corte $\mathrm{IDH},{ }^{56}$ en ocasión de la solicitud de consulta que hiciera Colombia respecto a las obligaciones estatales sobre el medio ambiente marino, en el marco de protección y garantía de los derechos a la vida e integridad personal, consagrados en los artículos 4 y 5 de la $\mathrm{CADH}$, debido a los proyectos de desarrollo relacionados con las exploraciones y extracciones de hidrocarburos emprendidos en los mares y océanos de la región, se reconoció la existencia de una relación innegable entre la protección del medioambiente y la realización de los derechos humanos. La Corte IDH destacó la relación de interdependencia e indivisibilidad que existe entre los derechos humanos, el medio ambiente y el desarrollo sostenible.

Concretamente, sostuvo que los Estados deben respetar y garantizar los derechos a la vida y a la integridad personal en relación con los daños ocasionados al medio ambiente. Así señala el deber de prevención de daños

${ }^{56}$ Opinión Consultiva OC-23/17, 15 de noviembre de 2017. 
ambientales significativos dentro o fuera de su territorio; regular, supervisar y fiscalizar las actividades realizadas dentro de su jurisdicción que puedan producir un daño significativo; realizar estudios de impacto ambiental; establecer un plan de contingencia para minimizar grandes accidentes ambientales y mitigar el daño producido.

En cuanto al principio de precaución, ${ }^{57}$ establece el deber de los Estados; por tanto, aquí aplica también para los juzgadores la actuación conforme al principio precautorio frente a los posibles daños graves e irreversibles al medio ambiente, aún en ausencia de certeza científica. ${ }^{58}$

\section{Conclusiones}

A pesar de los diferentes supuestos sobre los que yacen los derechos humanos, todos ellos se encuentran ligados por un vínculo común, que es la persona humana y su relación con el entorno. En este sentido, el más alto sentido de salud integral para una vida digna constituye no sólo un derecho fundamental, sino también el necesario contexto sobre el cual se puedan realizar todos los demás derechos de la persona.

Este artículo expone vínculos conceptuales entre los proyectos de desarrollo e infraestructura de la reforma energética y la salud. Las tensiones observadas entre los espacios para el ejercicio particular y el ejercicio público tienen relevancia de primer orden por cuanto nos da la pauta para generar las condiciones necesarias para el deseado equilibrio entre el desarrollo económico del país con el respeto a los derechos humanos.

Sin duda, el tema de los derechos humanos viene a impactar de manera muy importante en la reforma energética. En efecto, los proyectos de desarrollo e infraestructura que la apertura energética y eléctrica traerá consigo nos llevan a considerar los parámetros sobre los cuales se determinarán la viabilidad de estos proyectos.

Ante tal panorama, la justicia tiene mucho que decir, por lo que para el análisis de esta temática resulta de interés conocer el alcance y contenido del

\footnotetext{
${ }^{57}$ Este principio fue introducido por primera vez en los instrumentos internacionales en la Declaración de Río sobre el Medio Ambiente y el Desarrollo, Conferencia de las Naciones Unidas sobre el Medio Ambiente y el Desarrollo, Río de Janeiro, 3-14 de junio de 1992, Doc. ONU NCONP.I51/26/Rev.1 (Vol. 1), principio 15. Más tarde, fue reiterado en otros instrumentos, como la Convención Marco de las Naciones Unidas sobre el Cambio Climático, de la OEA; el Convenio de Estocolmo sobre Contaminantes Orgánicos Persistentes, de la OEA; y el Convenio sobre la Diversidad Biológica a nivel de Naciones Unidas.

${ }^{58}$ Opinión Consultiva OC-23/17, párrafo 180.
} 
derecho a la salud y su relación con el disfrute de otros derechos humanos. La realidad que imponen los derechos humanos se vuelve vital para cualquier proyecto en materia de hidrocarburos, electricidad o de desarrollo económico en México. Quedan, por tanto, dos enfoques por analizar: por un lado, resarcitorio en materia de reparación a los derechos vulnerados por los órganos públicos o privados; por el otro, preventivo respecto al análisis siempre interesante que nos plantean la ciencia, el desarrollo tecnológico y el respeto a los derechos humanos en el nuevo escenario constitucional.

\section{Referencias}

Carpizo, Enrique, "El control de convencionalidad y su relación con el sistema constitucional mexicano. Hacia una simple actividad protectora de derechos humanos", Boletín Mexicano de Derecho Comparado, nueva serie, año XLVI, número 138, septiembre-diciembre 2013, pp. 939-971.

Cossío, José R., "Primeras implicaciones del caso Radilla Pacheco", Cuestiones Constitucionales, Revista Mexicana de Derecho Constitucional, número 26, julio-diciembre 2012, pp. 31-63.

Suprema Corte de Justicia de la Nación, Protocolo de actuación para quienes imparten justicia en casos relacionados con proyectos de desarrollo e infraestructura, México, 2014. Disponible en: https://www.scjn.gob.mx/libreria/ paginas/protocolos.aspx.

Saldaña, Emmanuel, "Nuevo marco jurídico en materia energética establece acciones preventivas en materia social", Canal Judicial, 9 de abril de 2015. Disponible en: https://mail.google.com/mail/u/0/\#search/canal+judicial/14ca 08a5a2d52a54. Consultado el 18 de mayo de 2015.

Talavera, Pedro, "El derecho humano a la salud frente a las condiciones biosanitarias del planeta”, Revista Europea de Derechos Fundamentales, número 12, 2008.

Ventura Robles, Manuel, “Jurisprudencia de la Corte Interamericana en materia de derechos económicos, sociales y culturales”, Revista IIDH, volumen 40, 2004, p. 87-131. Disponible en: http://www.corteidh.or.cr/tablas/ R08064-3.pdf.

S/A, Conceden suspensión de plano a comunidades indígenas de Veracruz, Canal Judicial, 23 de abril de 2015. Disponible en: https://mail.google.com/ mail/u/0/\#search/canal/14ce7de1d2591167.

Decisiones judiciales

Corte Interamericana de Derechos Humanos

Velasquez Rodríguez vs Honduras. Sentencia de Fondo de 29 de julio de 1988, Corte Interamericana de Derechos Humanos. Disponible en: http://www.corteidh.or.cr/docs/casos/articulos/seriec_04_esp.pdf. 
Comunidad Mayagna (Sumo) Awas Tingni vs Nicaragua, Serie C No. 66 y Serie C No. 79, Sentencia Fondo, Reparaciones y Costas de 31 de agosto de 2001. Disponible en: http://www.corteidh.or.cr/docs/casos/articulos/Seriec_79 esp.pdf.

Comunidad indígena Yakye Axa vs Paraguay, Serie C No. 125, Sentencia Fondo, Reparaciones y Costas de 17 de junio de 2005. Disponible en: http://www. corteidh.or.cr/docs/casos/articulos/seriec_125_esp.pdf.

Comunidad Indígena Sawhoyamaxa vs Paraguay. Sentencia Fondo, Reparaciones y Costas de 29 de marzo de 2006. Disponible en http://www.corteidh.or.cr/ docs/casos/articulos/seriec_146_esp2.pdf.

Pueblo Saramaka vs Surinam. Sentencia Excepciones preliminares, Fondo, Reparaciones y Costas de 28 de noviembre de 2007. Disponible en: http://www. corteidh.or.cr/docs/casos/articulos/seriec_172_esp.pdf.

Acevedo Buendía y otros vs Perú, Sentencia de excepción preliminar, Fondo, Reparaciones y Costas de 01 de julio de 2009, Corte Interamericana de Derechos Humanos, párrafo 84. Disponible en: http://www.corteidh.or.cr/docs/casos/articulos/seriec_198_esp.pdf.

Comunidad indígena Xákmok Kásek vs Paraguay, Sentencia Fondo, Reparaciones y Costas de 24 de agosto de 2010, Corte Interamericana de Derechos Humanos. Disponible en: http://www.corteidh.or.cr/docs/casos/articulos/ seriec 214 esp.pdf.

Salvador Chiriboga vs Ecuador. Resolución de la Corte Interamericana de Derechos Humanos del 15 de mayo de 2011 Disponible en: http://www.corteidh. or.cr/docs/casos/articulos/seriec_179_esp.pdf.

Pueblo indígena Kichwa de Sarayaku vs Ecuador. Sentencia Fondo y Reparaciones de 27 de junio de 2012, Corte Interamericana de Derechos Humanos, párrafo 159. Disponible en: http://corteidh.or.cr/docs/casos/articulos/seriec_245 esp.pdf.

Gudiel Alvarez y otros (Diario Militar) vs Guatemala. Sentencia de Fondo, Reparaciones y Costas de 20 de noviembre de 2012.

Masacre de Santo Domingo vs Colombia. Sentencia de Excepciones Preliminares, Fondo y Reparaciones de 30 de noviembre de 2012.

Voto concurrente del Juez Eduardo Ferrer Mac-Gregor Poisot. Caso Suárez Peralta vs Ecuador. Excepciones Preliminares, Fondo, Reparaciones y Costas. Sentencia de 21 de mayo de 2013. Serie C No. 261. Disponible en: http://www. corteidh.or.cr/docs/casos/articulos/seriec_261_esp.pdf.

Opinión Consultiva OC-23/17, 15 de noviembre de 2017.

Tribunal Europeo de Derechos Humanos

Oneryildiz vs Turkey. 24 de noviembre de 2004. Disponible en: http://hudoc.echr.coe. int/sites/eng-press/pages/search.aspx?i=003-1204313-1251361.

L.C.B. vs the United Kingdom (application no. 23413/94). Disponible en: http://hudoc.echr.coe.int/sites/fra/pages/search.aspx?i=001-58176. 
Lopez Ostra vs Spain de 09 de diciembre de 1994. Disponible en: http://hudoc.echr. coe.int/sites/fra/pages/search.aspx?i=001-57905

Vilnes and Others vs Norway Disponible en: http://hudoc.echr.coe.int/sites/engpress/pages/search.aspx?i=003-4598614-5560664.

Suprema Corte de Justicia de la Nación

Contradicción de Tesis 293/2011. 03 de septiembre de 2013. Semanario Judicial de la Federación, décima época, libro 5, tomo I, Tesis: P./J.21/2014, p. 24. Registro 2006225.

Amparo en Revisión. 06 de enero de 2009. Publicada en Gaceta del Semanario Judicial de la Federación, novena época, tomo XXX, p. 6. Registro 165826.

Amparos en Revisión 498/2015; 499/2015; 500/2015; 270/2015; 410/2015 y AR 198/2015, 04 de noviembre de 2015. Suprema Corte de Justicia de la Nación. Segunda Sala. 
